\title{
CONTROVERSY
}

\section{Is the Children Act failing severely abused and neglected children?}

\author{
Nigel Speight, Jane Wynne
}

Is the Children Act failing severely abused and neglected children? The simple answer to this question in our opinion is an emphatic "Yes". The press carries articles almost daily concerning the plight of children in our society. ${ }^{12}$ Most paediatricians we have approached who have a special commitment to child protection work admit to feelings of near despair about the current state of child protection in this country. They feel that things are getting worse rather than better, and lay much of the blame for this on the Children Act and on the interpretation being put on this act by social workers, guardians ad litem, and the courts. We have received comments to the effect that the Children Act can be regarded as "A charter for abusive parents" or "A charter for abusive parents, lawyers and medical experts"! While these comments are anecdotal, impressionistic, and subjective we believe they deserve to be acknowledged as reflecting the deep sense of disillusion that exists, much of which we share.

\section{Background to the Children Act 1990}

It is perhaps unfair to expect perfection from any system or legislation in such a difficult and complex field as child abuse, and no developed society we are aware of has ever approached perfection. However, in this country we are entitled to expect that 27 years after the death of Maria Colwell we are entitled to legislation that would improve child protection significantly rather than make things worse. In our opinion it is the latter that has happened.

Before the Children Act, legislation and practice placed a stronger emphasis on protection of the child and insistence that abuse should stop. Early intervention was potentially firmer and more decisive. This protection was still far from perfect, as evidenced by the long list of children murdered while within the child protection system, each of which was the subject of an inquiry. ${ }^{3}$ Under the previous system plenty of latitude was left to social services and the courts to err on the side of rehabilitation, and the sequence of deaths reflected this.

The death of Jasmine Beckford in 1984 and the conclusions of the Blom-Cooper inquiry ${ }^{4}$ should have had a major influence on child protection work and on the drafting of the Children Act. This influence would surely have been towards placing greater emphasis on protection rather than rehabilitation. Unfortu- nately for abused children in the UK, all the lessons to be learnt from her death were submerged and forgotten because of the Cleveland crisis.

The authors of the Children Act appear to have been influenced more by a differing ideology emanating from the following sources:

- A persistent lobbying campaign by parents' rights groups

- Increasing desire for a more parent friendly approach on the part of one section of opinion within social work (much of this was based on logic we would regard as dubious based on "Messages from Research") ${ }^{5}$

- The populist reaction of our politicians to the whole problem of child abuse and neglect, which was exacerbated by their perceptions of the Cleveland crisis.

At no stage during the drafting of the Children Act does there appear to have been any counterbalancing input from a lobby for the rights of abused children. Indeed, apart from Childline [a telephone helpline for children] and the increasingly cautious NSPCC (National Society for the Prevention of Cruelty to Children) and hopefully increasingly the RCPCH (Royal College of Paediatrics and Child Health) such a lobby hardly exists in the UK today.

Thus, while Britain's abused and neglected children were entitled to expect that by 1990 our society should have been close to "getting it right", this is not what happened.

\section{Needs of severely abused and neglected children}

While there is a wide spectrum of severity of child abuse and neglect, we wish to concentrate on the severe end of the spectrum. It is reasonable to expect that we can at least get it right for this group of children.

Let us postulate the case of a young child (younger than 5 years) subject to severe abuse or neglect by severely damaged parents. Let us also postulate that the prospects for constructive change in the parents are small and that the quality of care available within the extended family leaves much to be desired.

It seems self evident that the best interests of such a child would be best served by:

- early intervention and full protection

- early adoptive placement 
- probable cessation of contact with the abusive parents (with the possibility of future contact only if in the child's interests). Society should make social workers feel empowered to take the above actions, and should praise them for their decisiveness and courage when they do. They should not be made to feel that they have failed as professionals because they were unable to work therapeutic miracles with the family.

Before 1990, the system at least allowed the possibility of such a decisive "happy ending". Social workers would have been able to apply for and get a Care Order via the magistrates' court with relatively little delay. The Care Order would give them full parental rights and a responsibility to make active plans in the child's best interests, with the help and support of the guardian ad litem. They would only need to return to court if there was an appeal or for approval of the adoption order. (We accept that there were plenty of failings in the actual delivery of such child protection before the Children Act - we are simply trying to establish whether the system is making effective child protection easier or harder.)

Since the Children Act, the chances of a decisive happy ending of the sort we have outlined have greatly diminished. It is less likely that social workers will seek to remove the child from home early on; instead a leisurely assessment process will be commenced with the child still in the abusive home. Social workers have to return to court for scrutiny of each and every decision made. Most importantly there has been a substantial shift in the threshold of proof that courts seem to require. Nowadays, it seems that you need more evidence to get a child onto the At Risk Register than you needed for a Care Order before 1990. Guardians and judges seem to require a "trial of rehabilitation" in nearly every case. Social workers feel they have to let the child be re-abused to show the judge (as enjoined by the Children Act) that they are only having recourse to legal proceedings as a last resort.

The end result is that if and when the child finally comes into care, he or she is more emotionally damaged, older, and consequently harder to place.

\section{Case 1}

Mary, aged 12 months, was the fourth child to a single mother who had been addicted to opiates for over six years. The three elder children were already subject to Care Orders and in a foster home as a sibling group, forlornly waiting an open adoption. All three have learning difficulties and emotional problems secondary to neglect in early childhood.

Mary was placed in foster care at birth with a plan for adoption. Despite this, contact was maintained with both her mother and her siblings twice a week (to keep the court happy?). A Care Order was finally obtained when Mary was 15 months old, but the mother appealed and there were no available court dates for four months. Meanwhile, Mary is becoming firmly attached to her foster mother.
This case demonstrates undue delay and consequent drift in decision making, with a systemic bias towards the rights of a neglectful parent against the interests of the child. While such a case could have happened before the Children Act, we believe that the Act has significantly increased the chances of such a sequence of events.

\section{Defects of the Children Act}

BIAS TOWARDS KEEPING ABUSED AND NEGLECTED CHILDREN WITHIN THEIR NATURAL FAMILIES

At a stroke, the Children Act has reinvented the sanctity of the blood link, although not in so many words. This ideological bias is central to the Act and its defects, and merits proper scrutiny. "The Act rests on the belief that children are generally best looked after within the family with both parents playing a full part and without resort to legal proceedings." 6

This statement would be unexceptional as a general aim for an ideal society in which child abuse and neglect do not exist. However, in the real world it is extremely debatable. Where is the evidence that abused and neglected children are best returned to abusing and neglectful parents? Surely in every case of significant abuse and neglect it should be a completely open question as to what is in the child's best interests.

In the absence of evidence, this resurgence of blood link ideology should be regarded as based on nothing stronger than a mixture of sentiment, political convenience, superstition, and wishful thinking. As physicians with a commitment to logical thought and evidence based practice, we are ideally placed to help social workers, the legal profession, and our politicians re-examine this central plank of the Children Act.

The authors of the Children Act might defend themselves by saying that the above bias is adequately counterbalanced by the principle stated elsewhere in the Act that "the interests of the child are paramount". However, this defence is in our opinion inadequate. First, the Act itself gives virtually no guidance as to what are the best interests of the child (what the judge thinks they are?). Second, the Act has already stated that in general children should be kept in their natural families so there is no escape from this closed loop.

This intellectual duet was played out with some poignancy in the case of Rikki Neavethe unfortunate 7 year old boy from East Anglia, UK, who was murdered a few days after his mother had repeated her request that social services take him off her hands lest she kill him. Social services declined to do so, the boy was murdered, and the mother was convicted of prior cruelty the extent of which would easily have justified a Court Order. Social services claimed in their defence that they were following the guidance of the Children Act in trying to keep children in their natural families

A frequent argument used in favour of keeping abused and neglected children within their natural families is that the alternative of care by social services can be worse. While superficially attractive this argument is in fact a further 
criticism of the Children Act. The problem with social services "care" is that it too often consists of a succession of short term placements culminating in an institutional placement, and this recipe seldom meets the true needs of the children concerned. The main reason for this sequence of events is laissez faire decision making and repeated unrealistic attempts at rehabilitation, which wastes valuable time.

The bias in the Act towards keeping children within their natural families is serving to accentuate these tendencies, so that when rehabilitation is eventually ruled out children are "hard to place" for adoption on grounds of age and emotional disturbance.

Additionally, the emphasis on contact between children and their abusive parents after reception into care constitutes a further practical barrier to successful adoptive and long term foster placements. Some of the case histories below illustrate these arguments.

THE CONCEPT OF PARTNERSHIP

Social workers are enjoined to work with abusive and neglectful parents in a spirit of partnership. The bias inherent in the Act is again apparent because the Act fails to state that parents must reciprocate to an equal degree and always be open and honest in their dealings with social workers. Neither is there any firm guidance to social workers as to how they should respond when parents do not enter into the spirit of partnership.

The concept of partnership has led to a significant shift in the balance of power at case conferences, with abusive and neglectful parents and their lawyers allowed virtually full participation throughout case conferences including the decision making process. The theoretical right of the child to participate does not in practice count for much, as they are usually too young to attend or too subjugated to speak out. Most crucially, the concept of full parental participation completely ignores the fact that in virtually every case of child abuse or neglect there is a basic conflict of interest between the parent and the child. A further aspect of the Act's prescription of partnership is that it is trivialising child abuse by decriminalising it. You do not enter into partnership with criminals during the investigation of a crime until the crime has stopped and the criminal has confessed and expressed remorse.

The weakness of the concept of partnership has been criticised further by Southall et al as a result of their experiences with covert video surveillance. $^{7}$ They conclude: "A proportion of serious child abuse is inflicted by severely disturbed, deceitful but plausible parents . . .partnership with parents - a process based on trust - would have failed to identify most of these children. Severe abusive behaviour may be less amenable to supportive family interventions and may require more assertive methods of investigation and decision making."

WORKINGS OF THE COURT SYSTEM

While the Children Act states the principle that there should be minimal delay for court cases involving children, like many well intentioned reforms it has achieved the opposite effect from that intended. Delays are greater than ever because of the transfer of cases from magistrates' courts to higher courts. The wasteful, inefficient, and adversarial nature of our judicial system continues as before, with the costs to the taxpayer greater than ever in the higher courts, with barristers' fees being added to an ever increasing army of medical experts.

Overall, one can sympathise with social services departments shrinking from going to court on grounds of cost alone. While the Act states that children's proceedings should be more inquisitorial and less adversarial, again the opposite has happened to what was intended, with an increasing number of "criminal" barristers deploying their adversarial skills to good effect in bullying child victims and professionals. In abolishing wardship, the Children Act appears to have transferred to care proceedings nearly all the disadvantages of wardship and only a few of the advantages.

THE CHANGE FROM “CARE" TO

"ACCOMMODATION/LOOKED AFTER"

Politicians changed the name of Windscale to Sellafield [a nuclear power station in the north west of Engand] because the former had a bad name. Now, the concept of a child being received into "care" has been restyled for political consumption because "care" had developed a negative image.

We find the new words "accommodation" and "looked after" distasteful. They appear to be designed to appease abusive and neglectful parents whose children have been removed"It's all right, we haven't really taken your children into care, we're just looking after them for you for a while."

The words "care" or "in need of care and protection" at least carried some recognition that all the child's needs (for love, care, and protection) might be met, even if they were often left unmet. The new terms are cold and not child centred, and we are surprised they have been accepted without demur by child care professionals.

We believe these linguistic niceties are significant. After all, why were we not given a "Children's Act" instead of a "Children Act". The latter reflects a wish to distance oneself from the needs of children as in "What are we going to do about the children Act?"

THE CONCEPT OF PARENTAL RESPONSIBILITY The Act promotes the concept of parental responsibility as a collection of duties, rights, and authority, which a parent has in respect of his or her child. The duty is to raise the child in moral, physical, and emotional health, and state that this is the fundamental task of parenthood.

As with the concept of "natural families" one would not argue with any of this in the absence of abuse or neglect. However, we would argue that when abuse or neglect occurs at the hands of parents, they have failed in their discharge of their parental responsibility, and that they should therefore naturally lose some if not all of their rights. 
The Act fails to state this, and implicitly encourages the concept of lifelong parental responsibility even after abuse and neglect. Are the political authors of the Act thinking here of the Child Support Act and their wish to extract money from absent fathers? It often seems to be an uphill struggle to convince the courts of the blindingly obvious where access by abusive parents is concerned and is clearly emotionally abusive to the child.

Case 2

A 6 year old boy's mother committed suicide after prolonged sadistic marital violence, which the boy had witnessed. A member of the mother's extended family had to fund her own legal team at great personal expense to (a) obtain custody and (b) stop access. No help whatsoever was forthcoming from social services or court welfare officers who remained aloof, failing to interview the boy and detect his real fear of his father.

Case 3

This case further illustrates the shift towards the "blood link" theory since the Act came into force. A girl was received into foster care at the age of 2 for neglect and emotional deprivation, and over the next 4 years rehabilitation proved impossible because of her mother's lifestyle and choice of partner. Before the Children Act, a decision was eventually made to seek an adoptive placement. Shortly after the Children Act, and with no other changes having occurred, a decision was made to rehabilitate. This was based on an assessment that excluded any consideration of the child's relationship with her mother's partner whom the child had not seen for 4 years. The judge approved the rehabilitation despite being informed that the partner had numerous convictions for burglary and violence. The placement broke down within a few weeks.

RAISING OF THE THRESHOLD OF PROOF OF ABUSE We believe that following the Children Act, courts are now demanding a higher level of proof of abuse than before. Presumably this is in response to the bias towards natural families already discussed. Instead of the standard of proof remaining (as it should) "on the balance of probability", courts seem to be veering more towards the criminal standard of "beyond all reasonable doubt". One judge actually stated " . . the more serious the allegation the less likely it is to have occurred, and hence the stronger should be the evidence before the court concludes that the allegation is established". According to this logic it should be harder to protect a child who has been raped than one who has been indecently assaulted.

Case 4

Katy, aged 3 years, lived with her mother who has moderate learning difficulties. Her father who is mentally ill lived locally. Katy was referred to the paediatrician because of concern that she was sad, withdrawn, failing to thrive, and had language delay. Finger tip bruising was noted on the thighs, as well as signs highly suggestive of penetrative anal abuse. The child was left in the home while an assessment was begun. Over the next 6 months the child "disclosed" sexual abuse and physical signs were detected on three further occasions. Finally and grudgingly, the local authority solicitor agreed that there was now enough evidence to test in court.

What price are abused children paying in terms of re-abuse when the legal process indulges in "the crime of diagnostic greed"?

EFFECTS ON EARLY INTERVENTION

As a result the above factors, it is only to be expected that front line social workers will become so discouraged at all the barriers to effective intervention that they are tempted to cover up cases at source. As they are effectively operating a closed loop system whereby the vast majority of new cases end up at home, why go to all the trouble and expense of having a case conference, putting the child on the register, and conducting a detailed assessment if this is all mere window dressing?

We have noted a marked reduction in the willingness of some social workers to listen to older children disclosing emotional deprivations/neglect and even sexual abuse.

Case 5

Darren, aged 15, was due to be discharged from hospital after an admission for stabilisation of his diabetes. He told the ward sister he did not want to go home because he could not stand it any longer. $\mathrm{He}$ complained that his mother was drinking excessively and always in a daze from her tranquillisers, and that she was mismanaging the family finances. Darren was having to care for his younger sister, do most of the housework, and study for his GCSEs [public school examinations]. He requested reception into foster care.

A social worker interviewed him and gave him no assurances that his request would be acted on. Allegedly he told Darren "You don't look too malnourished to me." Faced with an impasse, the paediatrician put Darren in touch with a solicitor who acted for him and forced social services into getting him a foster home in which he thrived and did well in his GCSEs.

OVERALL RESULTS OF THE CHILDREN ACT

As argued above, the Children Act in many ways acts as a deterrent to social workers intervening firmly in cases of abuse and neglect. While all statistics in this area are open to arguments about interpretation, it is noteworthy that between 1991 and 1995 (the first four years of the operation of the Act) there was a precipitous decline in the number of children "in care", from about 60000 in 1991 to 40000 in $1995 .{ }^{8}$ While the authors of the Act might regard this as just the sort of result they wished for, we regard it as unlikely that abused and neglected children were being taken into care unnecessarily before 1991 and that there had been a spontaneous drop of $33 \%$ in the incidence of abuse and neglect over these four years, and that there had been a sufficient improvement in preventive and therapeutic 
work with the abusive families over this time to achieve a change of this magnitude.

POSITIVE ASPECTS OF THE CHILDREN ACT

To our knowledge the Children Act has not been subject to any serious criticism since its inception. It even has its own "good news" bulletin to present a positive gloss on how well it is working. Accordingly, we would like to leave this article as purposely unbalanced to stimulate discussion. We acknowledge that there are many positive features of the Children Act, including:

- the inclusion of "likely future harm" as grounds for care proceedings

- the increased emphasis on the need to ascertain and respect the child's wishes

- the inclusion of private schools in the responsibilities of social services.

We also acknowledge that where all agencies share a confident view as to what are the best interests of the child, the Children Act can prove perfectly effective as a vehicle for achieving this; however, we believe this is a relatively rare occurrence for the reasons given.

In 1990, a group of child care professionals from Boston wrote a cri $d u$ coeur for abused children in the USA. They highlighted the many failings of their judicial and child protection systems, and called for paediatricians to act as advocates for their patients over and above initial diagnosis and reporting. Many of the failings they describe are mirrored in this country today, eight years after the introduction of the Children Act, and we commend the article to all readers. ${ }^{9}$

Perhaps this challenge to advocacy for abused and neglected children is one that the Royal College of Paediatrics and Child Health can take up afresh.

1 Davies N. The Guardian, 3-6 June 1998.

2 Hugill B. The Observer, 14 June 1998.

3 Lessons from inquiry reports. Child abuse: a study of inquiry reports 1973-81. London: HMSO, 1982.

$4 \mathrm{~A}$ child in trust. Report of Panel of Inquiry into the circumstances surrounding the death of fasmine Beckford. Middlesex: Kingswood Press, 1985.

5 Department of Health. Messages from research. Studies in child Department of Health. Messages from
protection. London: HMSO, 1995.

6 An introduction to the Children Act 1989. London: HMSO, 1989.

7 Southall DP, Plunkett MCB, Banks MW, Falhov AF, Samuels MP. Covert video recordings of life-threatening child abuse: lessons for child protection. Pediatrics 1997;100: 735-60.

8 The Utting report. People like us-the review of safeguards for children living away from home. London: HMSO, 1997.

9 Jellinek MS, Murphy JM, Bishop S, Poitrast F, Quinn D. Protecting severely abused and neglected children. An unkept promise. N Engl f Med 1990;323:1628-30. 